\title{
ESTUDO DA INFLUÊNCIA DOS SISTEMAS AUXILIARES DO MOTOR NA DINÂMICA LONGITUDINAL DE UM VEÍCULO DE PASSAGEIROS.
}

\author{
Tiago Priolli Monteiro ${ }^{1}$ e Antonio Carlos Canale $^{2}$ \\ ${ }^{1}$ Escola de Engenharia de São Carlos - USP \\ ${ }^{2}$ Escola de Engenharia de São Carlos - USP \\ E-mails: tiago.monteiro@usp.br, canale@sc.usp.br
}

\section{RESUMO}

O aumento no rigor das normas de emissão de poluentes levou a indústria automobilística a direcionar grandes recursos no desenvolvimento de tecnologias hibridas e elétricas para adequar-se a esse novo cenário, porém pouca ênfase tem sido dada na influência dos sistemas auxiliares do motor (Bombas, alternador e compressor) na dinâmica e no trabalho total desenvolvido pelo motor. Desenvolveu-se no MATLAB Simulink um simulador completo de dinâmica direta de um veículo de passageiros, onde foram introduzidos no motor dados referentes à bomba de óleo, à bomba de água, ao alternador e ao compressor do ar condicionado. Este veículo foi submetido ao New European Drive Cycle (NEDC) e ao Federation Test Procedure (FTP) que são amplamente utilizados na indústria automobilística. Como resultado obteve-se que os auxiliares foram responsáveis pelo de consumo de 41-49\% da energia total gerada no motor, sendo o compressor de ar condicionado e alternador os maiores responsáveis, com consumos de $26-33 \%$ e $8-10 \%$ respectivamente. Tais resultados deixam explicita a grande influência desses sistemas no consumo total do veículo e salientam sua importância na otimização dos futuros motores.

\section{INTRODUÇÃO}

O aumento das restrições na exaustão de poluentes em autoveículos pelos governos, devido a preocupações com o meio ambiente e aquecimento global (figura 1), tem pressionado a indústria automobilística a melhorar a eficiência de seus motores de combustão interna.

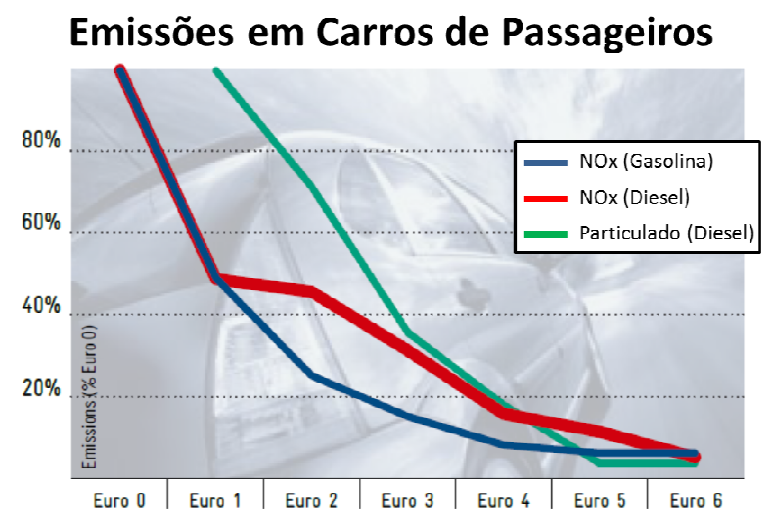

Figura 1. Emissões em Carros de Passageiro [1]. 
No entanto, com a aproximação nos últimos anos do nível de zero emissão, reduções se tornaram extremamente difíceis de conseguir. Apresentando, em conjunto com o aumento do preço, e futura escassez, de combustíveis derivados do petróleo, um desafio enorme no futuro desta indústria.

Atualmente uma das maiores penalidades na eficiência do trem-de-força nos veículos é a carga devida aos vários auxiliares movidos pelo motor. Apesar de serem indispensáveis para o funcionamento e conforto do veículo, auxiliares como: bomba d'água, bomba de óleo, alternador e compressor do ar condicionado, requerem quantidades consideráveis de energia sem contribuir diretamente para a movimentação do veículo.

Objetivou-se, então, estimar o impacto desses sistemas na dinâmica longitudinal de um veículo de passageiros, principalmente nos ciclos rodoviários utilizados na indústria para se mensurar consumo.

Para realizar essa tarefa, foi utilizada a ferramenta Simulink do MatLab. Nela foi desenvolvido um simulador de dinâmica direta para um veículo de passageiros, no qual foram incluídos os sistema auxiliares (Bomba D’água, bomba de óleo, alternador, compressor do ar condicionado) dimensionados seguindo modelos disponíveis na literatura.

\section{DESENVOLVIMENTO DO SIMULADOR}

Em um veículo de passageiros existem quatro forças principais que impactam diretamente sua resposta dinâmica:

\subsection{Força de tração}

A força de tração, expressa matematicamente pela eq 1, quando transportada para o simulador foi dividida em três blocos principais: trem-de-força, perdas inerciais e um terceiro limitando a força máxima permitida pelo contato pneu/pavimento.

$F_{\text {powertrain }}=\left(T_{\theta}-T_{\text {awx }}\right) \times N_{t f} \times \eta_{t f} / r-F_{\text {lloggeg }}$

Onde:

$\mathrm{Te}=$ Torque do motor [N.m]

Taux $=$ Torque dos sistemas auxiliares do motor [N.m]

$\mathrm{Ntf}=$ razão de transferência combinada da caixa de transmissão e diferencial

$\eta \mathrm{tf}=$ eficiência combinada da caixa de transmissão e diferencial

$\mathrm{r}=$ raio dinâmico da roda $[\mathrm{m}]$

FIlosses $=$ Perdas inerciais da transmissão, motor, diferencial e rodas $[\mathrm{N}]$

O simulador do trem-de-força, que representa o primeiro termo do segundo membro da equação 1 , pode ser visto em detalhes na figura 2 . 


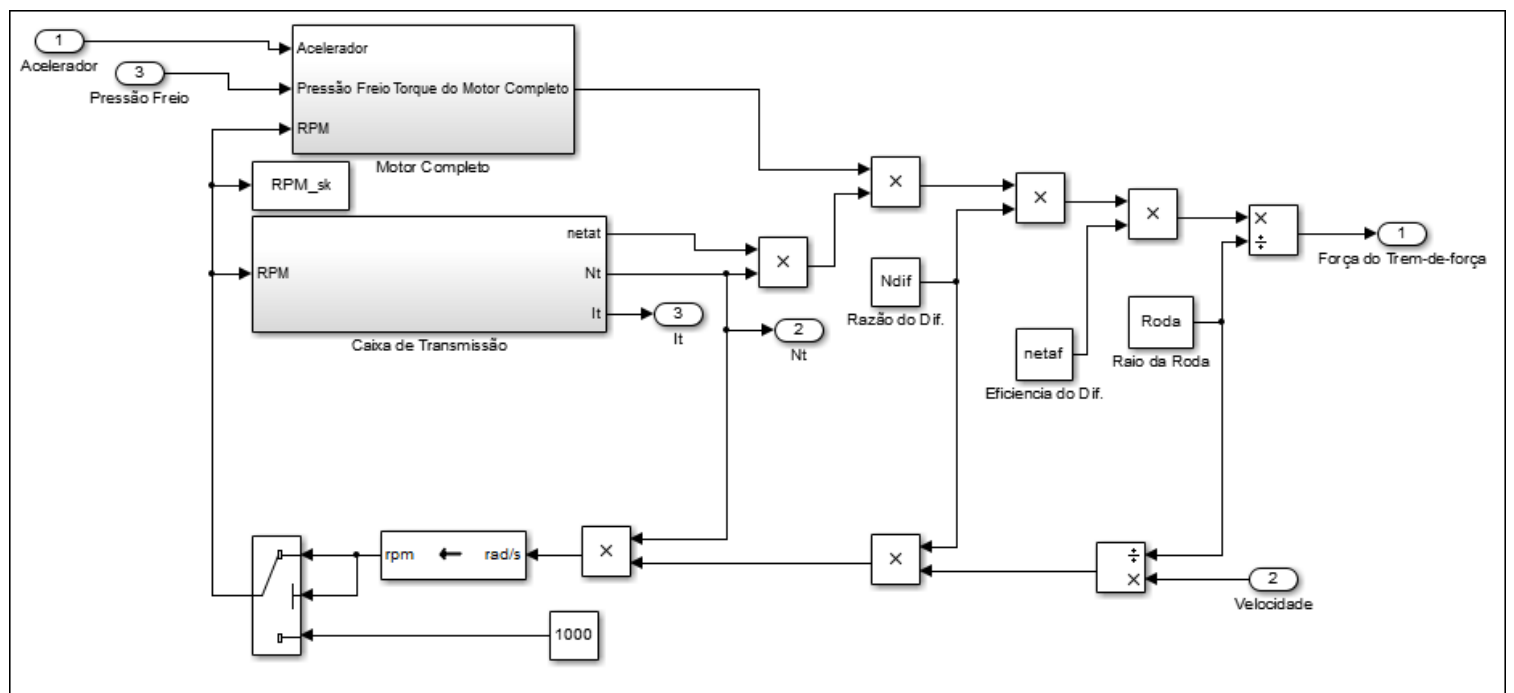

Figura 2. Simulador Trem-de-força

A figura 3 mostra o conteúdo do subsistema "Motor Completo", nele se encontra o simulador dos auxiliares em conjunto com o motor mapeado e um bloco para controle de marcha lenta. O controle de marcha permite ao motor cortar o consumo de combustível durante desacelerações até que este atinja uma rotação mínima de 1500rpm.

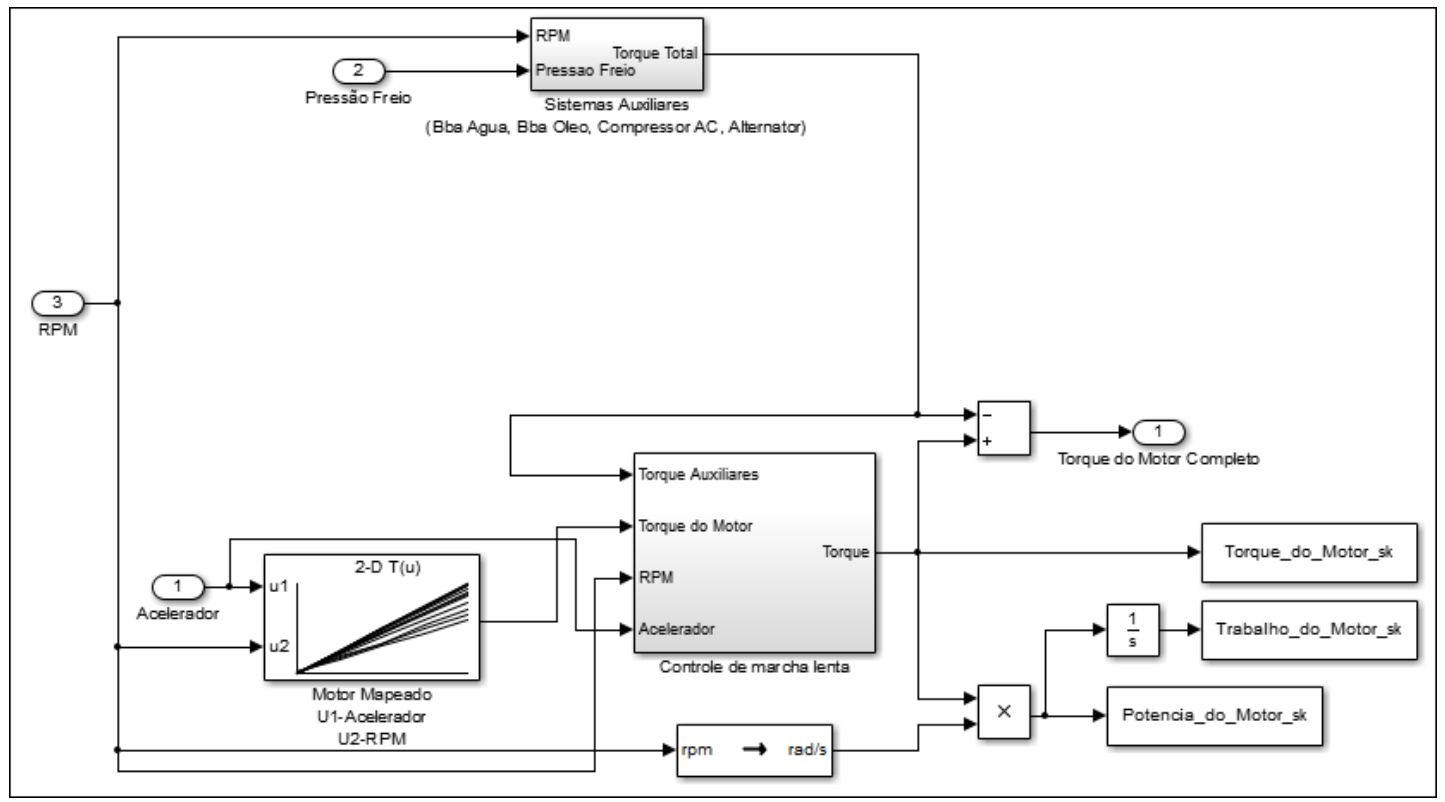

Figura 3. Simulador Motor Completo

Como relatado na introdução no desenvolvimento do simulador foram selecionados quatro sistemas auxiliares, e seus atuadores ligados ao motor, para estudo neste artigo: $\mathrm{O}$ sistema de arrefecimento (bomba d'água), o sistema de lubrificação (bomba de óleo), o sistema elétrico (alternador) e o sistema do ar condicionado (compressor). O simulador completo desses sistemas é apresentado na figura 4 . 


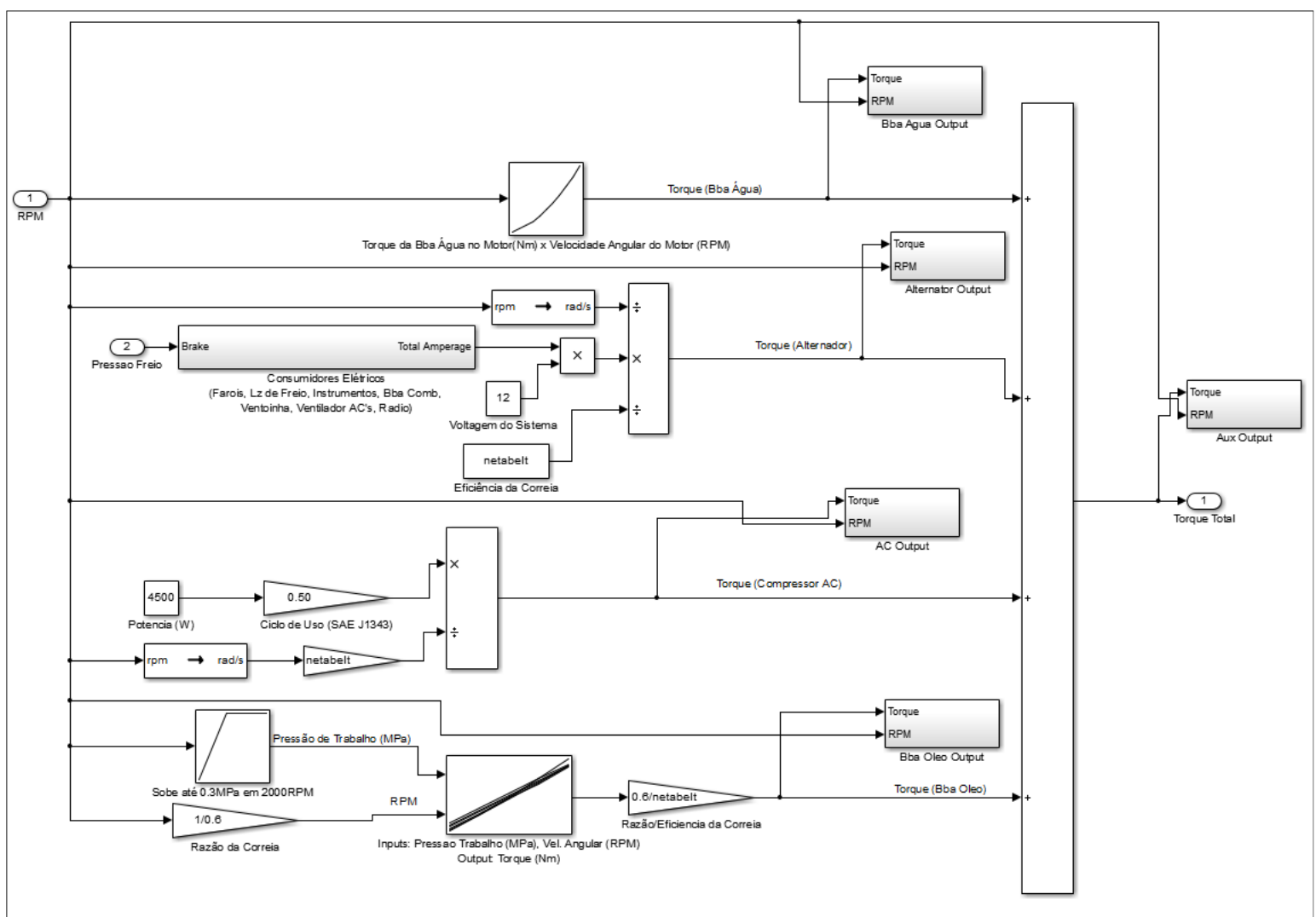

Figura 4. Simulador dos Sistemas Auxiliares do Motor

Além desses, outro sistema que tem influência no gasto de combustível do veículo é a direção assistida, mas como os ciclos empregados na simulação se desenvolvem sem curvas, esse sistema não foi incluído.

O dimensionamento das cargas dos auxiliares no motor apresenta uma dificuldade, devido ao fato delas serem desprezadas em muitos estudos de desempenho e, não serem precisamente controladas, nem padronizadas, nas aplicações da indústria.

Portanto, para obter valores condizentes com a realidade, cada sistema foi abordado em separado:

\subsubsection{Sistema de arrefecimento}

O estudo da cavitação na bomba d'água de um motor 2.0 movido à gasolina [2] resultou no levantamento de gráficos de Torque no motor x rotação para essa bomba em cada temperatura de operação. Admitindo-se o motor já em regime permanente, com temperatura de $\approx 90^{\circ} \mathrm{C}$, no início dos ciclos de consumo pode-se obter o gráfico abaixo (Gráfico 1): 


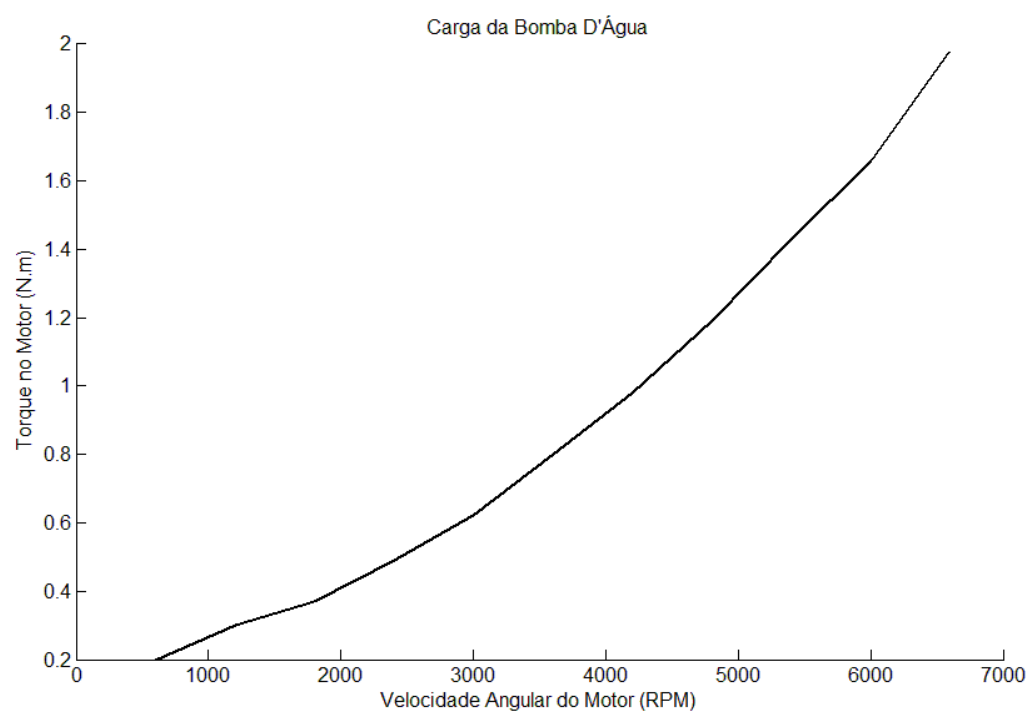

Gráfico 1. Torque da Bomba D'água no Motor[2].

\subsubsection{Sistema de lubrificação}

Este sistema apresentou a maior dificuldade, devido à escassez de trabalhos realizados sobre o assunto. Na construção do cálculo da carga foram então utilizados dois gráficos: $\mathrm{O}$ gráfico 2 relaciona o aumento da pressão no sistema com rotação do motor, enquanto o gráfico 3 relaciona o torque na bomba com a pressão no sistema e a rotação da bomba. Utilizando uma relação de 0.6 na transmissão desse torque para o motor foi possível estimar a carga desse sistema.

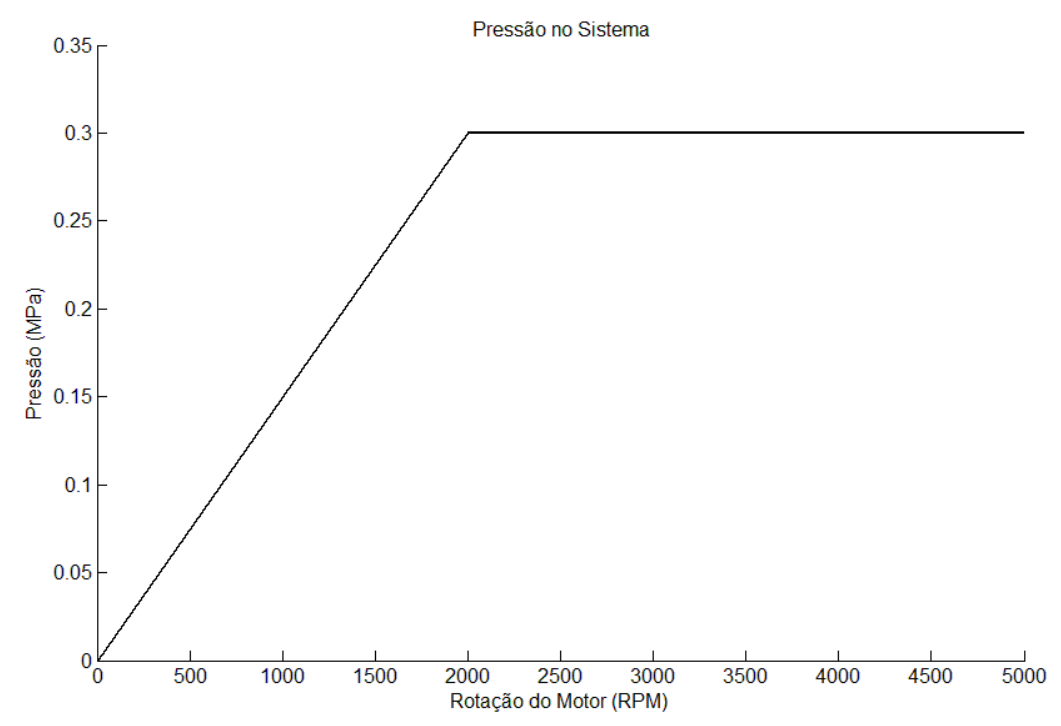

Gráfico 2. Pressão no sistema de lubrificação 


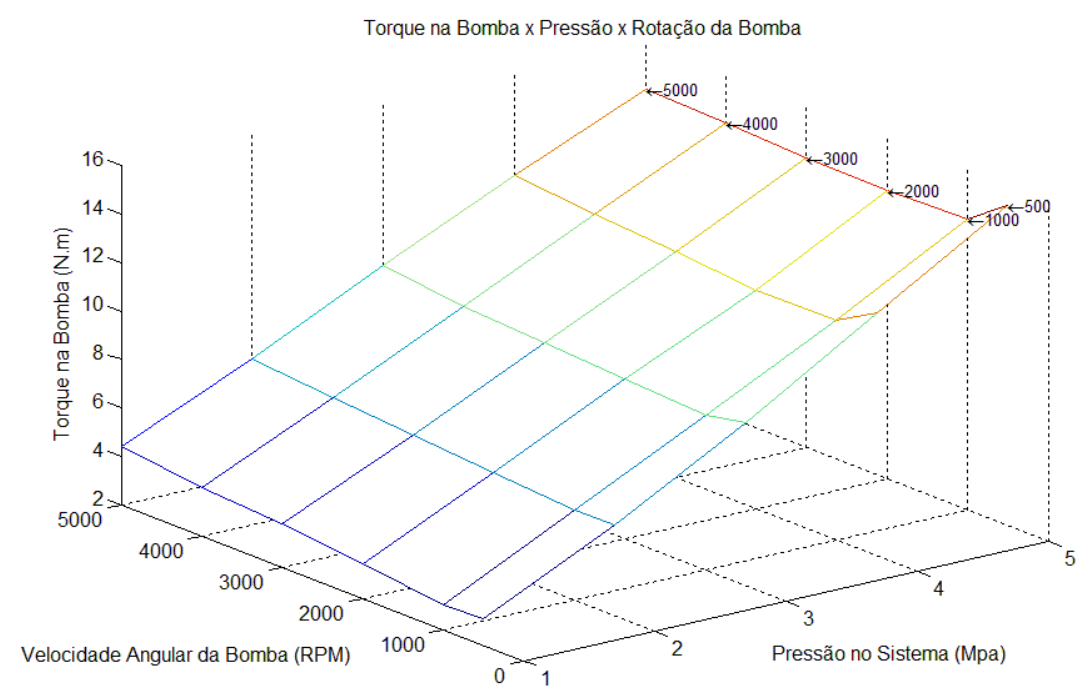

Gráfico 3. Torque da bomba de óleo[3].

\subsubsection{Sistema elétrico}

A carga do alternador no motor é função direta da carga elétrica requerida pelo veículo. Utilizando-se a norma SAE J1343 [4] pode-se obter estimativas para a carga elétrica, em amperes, dos diversos consumidores elétricos do veículo. A equação 2 é então utilizada para se calcular o torque do alternador visto pelo motor.

$T_{\text {alt }}=\frac{I_{\text {cons }} \times V_{\text {sist }}}{\omega_{\text {motor }} \times \eta_{\text {eorria }}}$

(2)

Onde:

Talt $=$ Torque do alternador no motor $[\mathrm{N} . \mathrm{m}]$

Icons $=$ Corrente requerida pelos consumidores $[\mathrm{A}]$

Vsist $=$ Voltagem do sistema elétrico $[\mathrm{V}]$

$\omega$ motor $=$ Velocidade angular do motor $[\mathrm{rad} / \mathrm{s}]$

$\eta$ correia $=$ Eficiência na transmissão por correia

Os consumidores considerados, sua corrente requerida e ciclo de uso se encontram na tabela 1. A voltagem de trabalho utilizada foi $12 \mathrm{~V}$.

\begin{tabular}{|l|c|l|}
\hline Consumidor & Corrente Requerida [A] & Ciclo de uso \\
\hline Luz de Freio & 4,3 & Quando freio é utilizado \\
\hline Radio & 4,4 & Ligado (100\%) \\
\hline Luzes Frontais & 10 & Ligado (100\%) \\
\hline Luzes Traseiras & 1.2 & Ligado (100\%) \\
\hline Luzes do Painel & 1 & Ligado (100\%) \\
\hline Ventilador do A/C & 65 & Ligado (50\%) \\
\hline Bomba de Combustível & 2.6 & Ligado (100\%) \\
\hline Indicadores do Painel & 1 & Ligado (100\%) \\
\hline Ventoinha do Motor & 70 & Ligado (7\%) \\
\hline
\end{tabular}

Tabela 1. Cargas Elétricas dos Consumidores[4]. 


\subsubsection{Sistema do ar condicionado}

No cálculo da carga do compressor do ar condicionado foi utilizada também a estimativa proposta pela norma SAE J1343. Nesta estimativa utiliza-se a potência máxima do compressor em conjunto com um fator de ciclo. Este fator representa o tempo de uso de do acessório, em conjunto com as cargas parciais que ele é usado. A carga pode então ser obtida pela equação 3 .

$T_{\text {compr }}=\frac{P_{\text {max }} \times F_{\text {oiolo }}}{\omega_{\text {motor }}}$

Onde:

Tcompr $=$ Torque do compressor no motor [N.m]

Pmax $=$ Potência máxima do compressor

Fciclo $=$ Fator de ciclo

A potência máxima utilizada foi de $4,5 \mathrm{~kW}$, e o fator de ciclo proposto na norma para ciclos predominantemente urbanos é 0,5 .

A união do simulador do trem-de força com o cálculo das forças inerciais e o limite de tração do contato pneu pavimento é apresentada na figura 5.

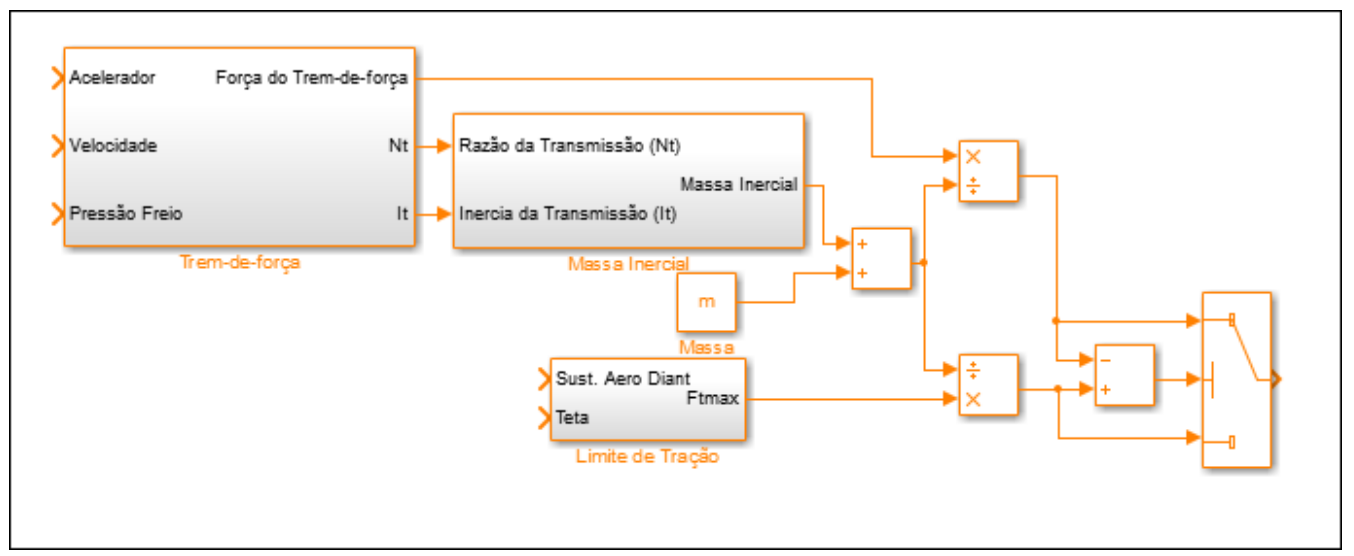

Figura 5. Simulador da força de tração

\subsection{Força de Frenagem}

A força de frenagem total é dada pela equação 4. Esta equação apresenta uma forma simplificada de cálculo onde os ganhos discretos dos vários módulos que compõem o sistema de freios são resumidos em apenas dois ganhos básicos, um para o conjunto dianteiro e outro para o conjunto traseiro.

$F_{\text {Freio }}=2 \times G_{f} \times P_{f} / r+2 \times G_{r} \times P_{r} / r$

Onde,

FFreio $=$ Força de frenagem total $[\mathrm{N}]$

Gf = Ganho dos freios dianteiros [m.N/psi]

$\mathrm{Pf}=$ Pressão de entrada dos freios dianteiros [psi]

$\mathrm{Gr}=$ Ganho dos freios traseiros [m.N/psi]

$\operatorname{Pr}=$ Pressão de entrada dos freios traseiros [psi] 
O sistema de freios foi representado no simulador pelo bloco mostrado na figura 6 .

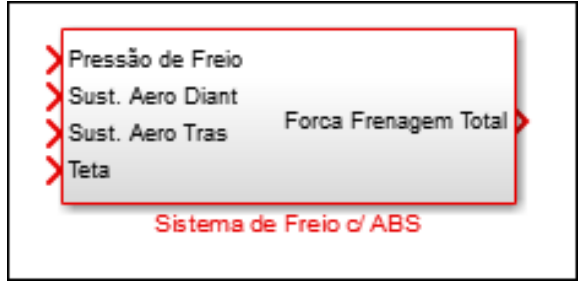

Figura 6. Bloco do simulador do sistema de freio

\subsection{Forças de Resistência}

O veículo está sujeito a duas forças de resistência principais: a força de resistência aerodinâmica (equação 5) e a força de resistência ao rolamento (equação 6).

$D_{A}=(1 / 2) \times \rho \times V^{2} \times C_{D} \times A$

$R_{x}=f_{p} \times W$

Onde,

$\mathrm{DA}=$ Força aerodinâmica longitudinal $[\mathrm{N}]$

$\rho=$ densidade do ar $[\mathrm{Pa}]$

$\mathrm{V}=$ velocidade do veículo $[\mathrm{m} / \mathrm{s}]$

$\mathrm{CD}=$ Coeficiente aerodinâmico de resistência

$\mathrm{A}=$ Área frontal do veículo [m2]

$\mathrm{Rx}=$ Resistência ao rolamento $[\mathrm{N}]$

$\mathrm{fr}=$ Coeficiente de rolamento

Essas forças foram representadas no simulador pelo bloco apresentado na figura 7.

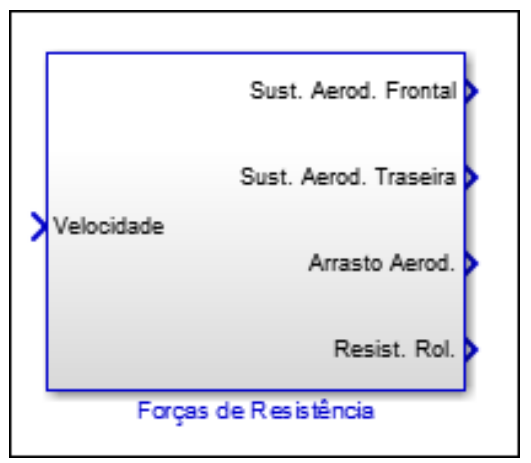

Figura 7. Bloco do simulador das forças de resistência

\subsection{Planta do veículo completo em simulink}

A combinação das forças discutidas nas três subseções anteriores resulta na equação do movimento longitudinal do veículo (Equação 7).

$$
F_{\text {engine }}-F_{\text {Freio }}-D_{A}-R_{x}-F_{\text {slope }}=\left(m+m_{l}\right) \times a
$$

Onde,

Fengine $=$ Força desenvolvida pelo motor $[\mathrm{N}]$

Fslope $=$ Projeção da força peso na longitudinal devida à rampas $[\mathrm{N}]$

$\mathrm{m}=$ massa do veículo $[\mathrm{kg}]$

$\mathrm{mI}=$ massa inercial $[\mathrm{kg}]$ (representa as perdas inerciais da equação 1) 
A figura 8 apresenta a combinação dessas forças no Simulink.

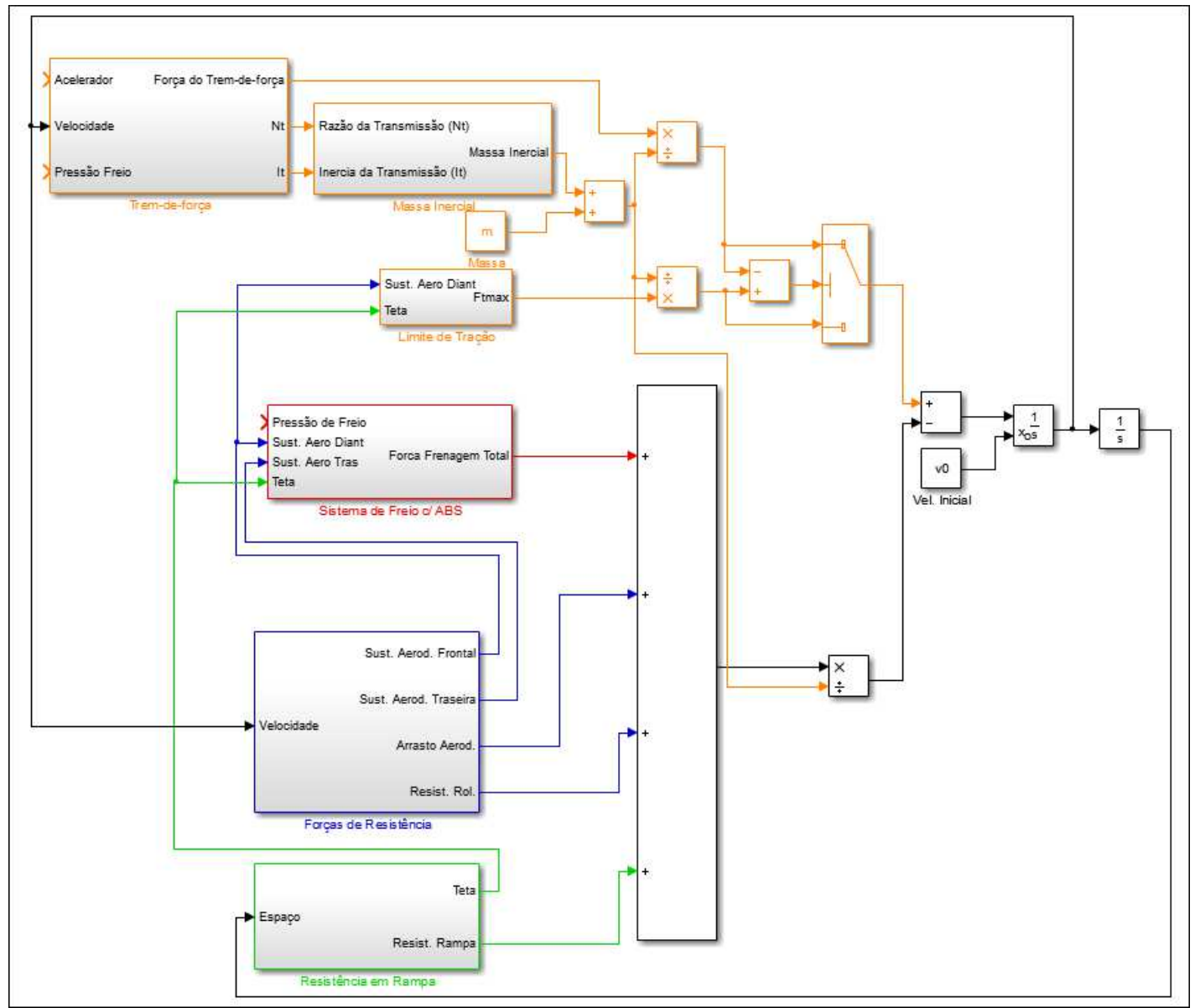

Figura 8. Simulador completo da planta do veículo

\subsection{Controlador do Veículo}

Com o objetivo de testar a planta do veículo nos ciclos automotivos NEDC (figura 9) e FTP (figura 10), foi desenvolvido um controlador composto de uma ação integral (I) e de uma ação proporcional-integral-derivativa (PID).

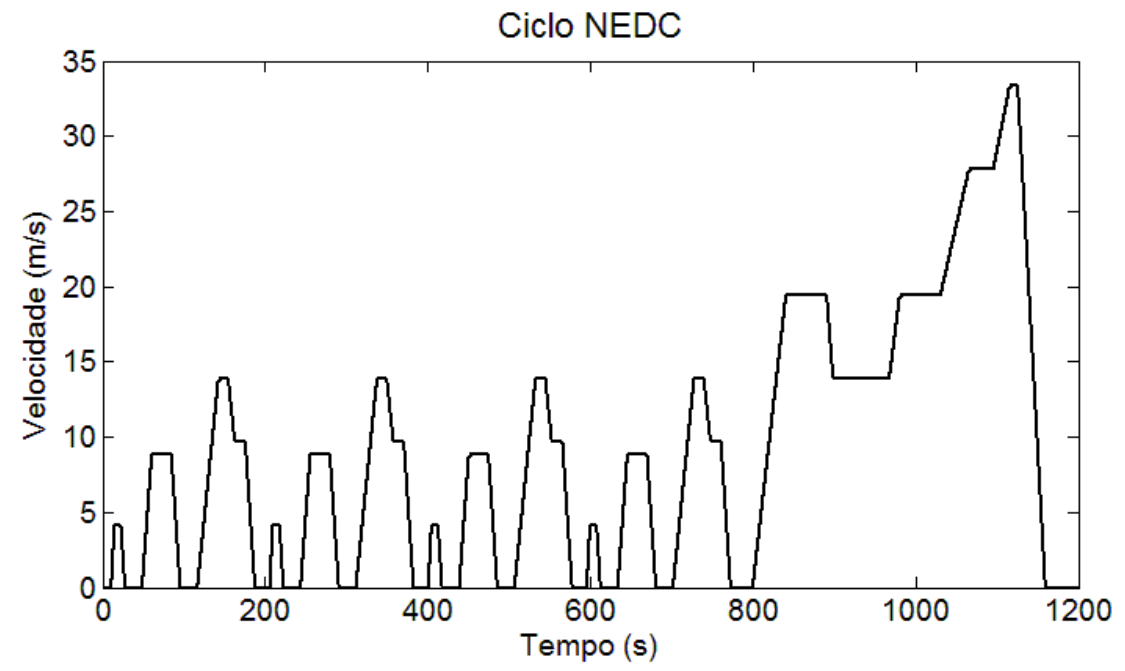

Figura 9. New European Drive Cycle 


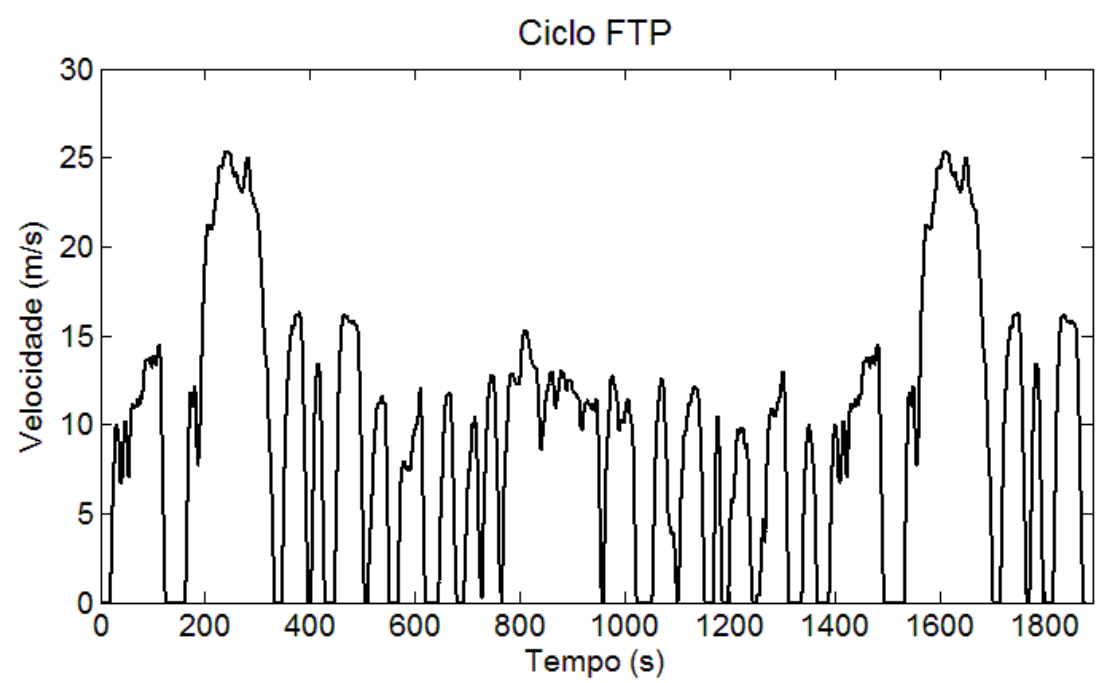

Figura 10. Federation Test Procedure

A figura 11 mostra a representação esquemática do controlador, onde "r" é a velocidade de referência do ciclo automotivo e y é a velocidade da planta do veículo.

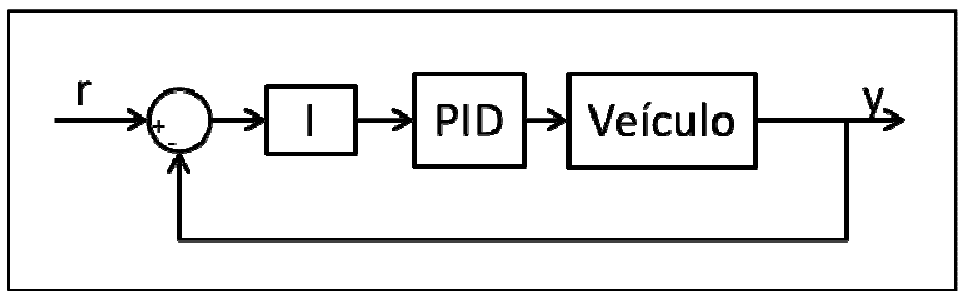

Figura 11. Esquema do controlador da planta do veículo

A inclusão de controlador integral antes do PID padrão se faz necessária pela característica de segundo grau da planta do veículo. Esta característica é associada à força de resistência aerodinâmica, e imprime no comportamento da planta um erro de regime permanente nas acelerações quando controlada apenas por um PID.

O sistema de controle, apresentado no ambiente do Simulink na figura 12, atua sobre a planta em dois parâmetros, quando a velocidade de referência é maior que a do veículo a resposta do controlador é direcionada para o acelerador, e quando a velocidade de referência for menor que a do veículo a resposta é direcionada para os freios.

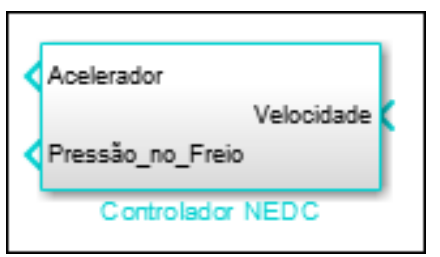

Figura 12. Bloco do simulador do controlador

A figura 13 mostra o controlador integrado com a planta no ambiente de simulação do Simulink. 


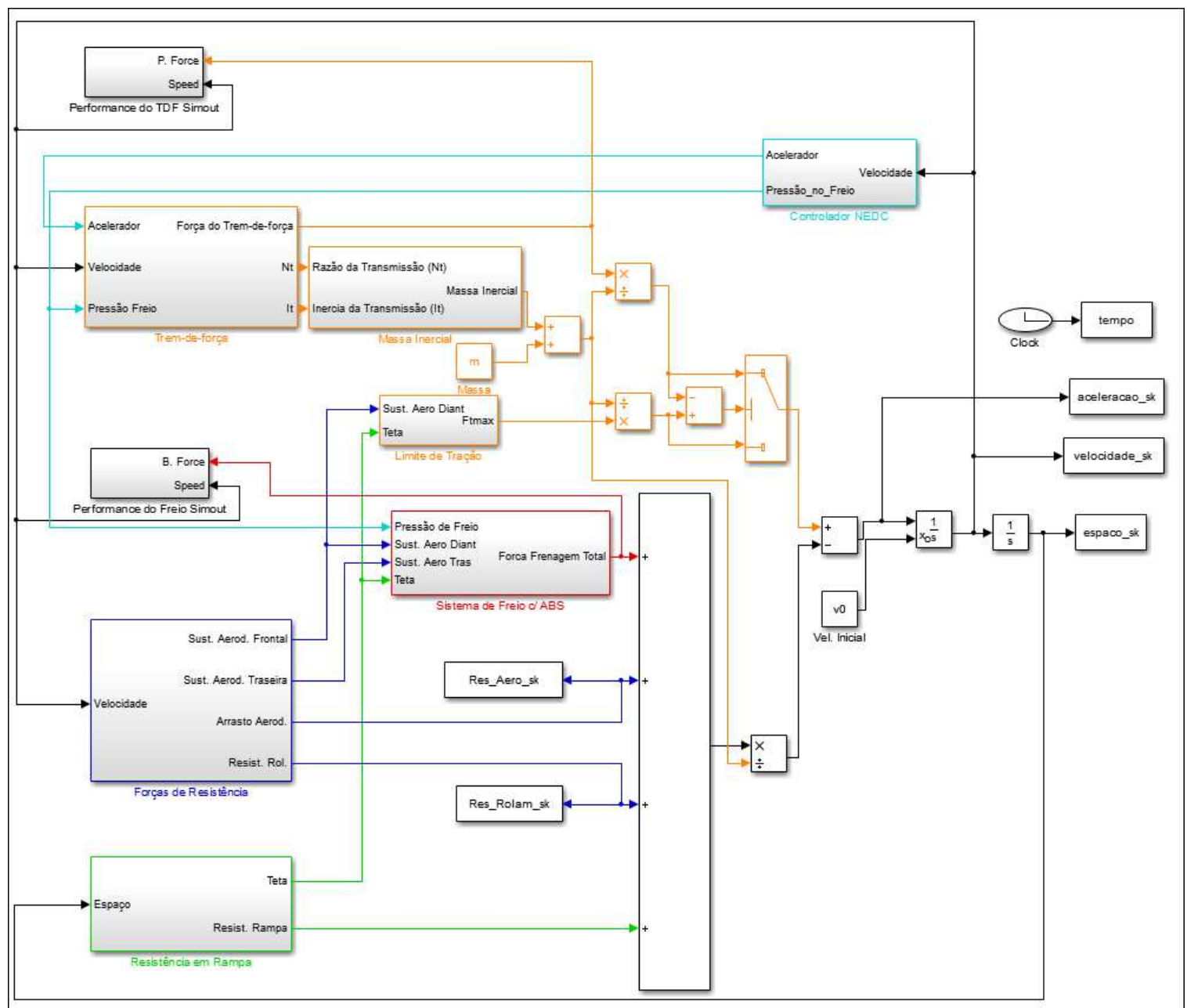

Figura 13. Simulador completo do veículo

\section{RESULTADOS}

Inicialmente, para se aferir a eficácia do controlador, foi levantado um gráfico com as forças aplicadas no veículo durante o ciclo NEDC (Gráfico 4). 


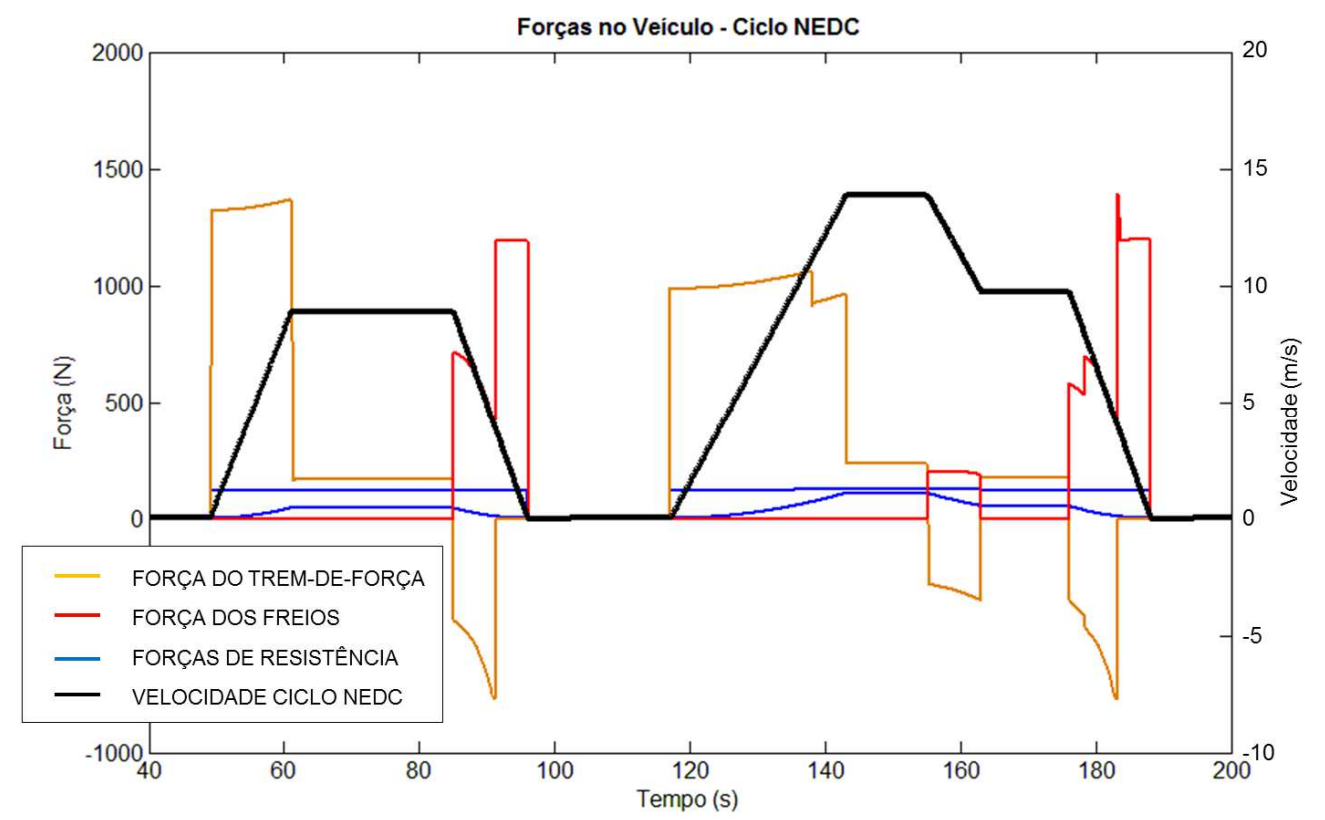

Gráfico 4. Forças no veículo controlado

Neste gráfico é possível observar a interação da força do trem-de-força com o sistema de freio. Quando o veículo inicia uma frenagem, o trem-de-força trabalha em conjunto com o freio, pois o combustível é cortado visando economia. A partir de certa velocidade o controle de marcha lenta entra em ação e a força do trem-de-força no veículo vai à zero.

Analisando o gráfico dos torques na transmissão do veículo (gráfico 5) em conjunto com o ciclo vemos como o corte de combustíveis afeta o torque do motor, e como este torque trabalha em conjunto com o torque resultante dos auxiliares.

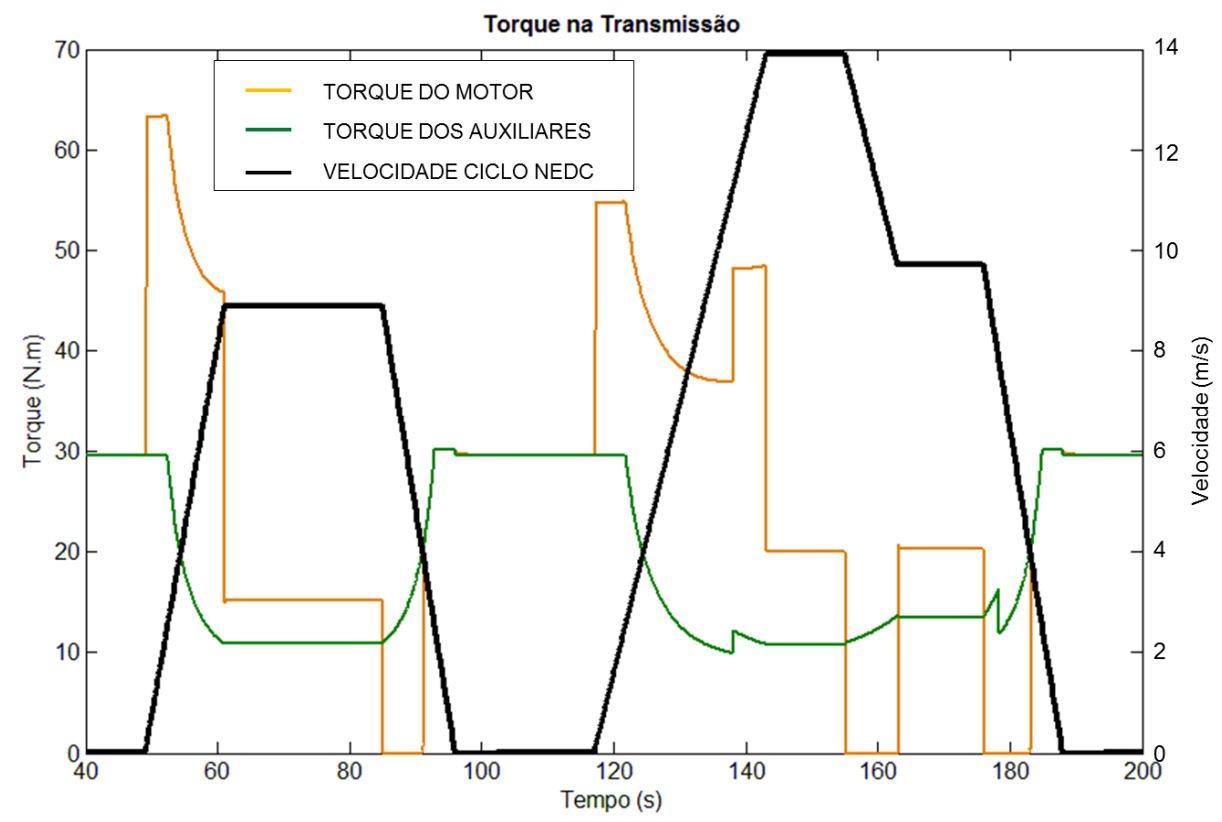

Gráfico 5. Torques na transmissão 
Finalmente, executando ambos os ciclos foram levantados os trabalhos realizados pelos auxiliares, pelo motor e pelo sistema de freio do veículo. A tabela 2 apresenta os resultados para o ciclo NEDC e a tabela 3 para o ciclo FTP.

\begin{tabular}{l|ccccc}
\hline Sistema & $\begin{array}{l}\text { Trabalho } \\
\text { aceleração }(\mathrm{MJ})\end{array}$ & $\begin{array}{l}\text { \% } \\
\text { de propulsão }\end{array}$ & $\begin{array}{c}\text { Trabalho } \\
\text { frenagem }(\mathrm{MJ})\end{array}$ & $\begin{array}{l}\text { \% do } \\
\text { de frabalho }\end{array}$ \\
\hline Compressor A/C & $-2,42$ & 26,8 & 0,29 & 22,8 \\
Alternador & $-0,75$ & 8,3 & 0,10 & 7,9 \\
Bomba de óleo & $-0,39$ & 4,4 & 0,05 & 3,9 \\
Bomba d'água & $-0,16$ & 1,8 & 0,02 & 1,6 \\
Total Auxiliares & $-3,72$ & 41,3 & 0,46 & 36,2 \\
Propulsão & 9,01 & 100 & & 100 \\
Frenagem & & & & \\
\hline
\end{tabular}

Tabela 2. Trabalhos no ciclo NEDC

\begin{tabular}{l|crccc}
\hline Sistema & $\begin{array}{l}\text { Trabalho } \\
\text { aceleração }(\text { MJ) }\end{array}$ & $\begin{array}{l}\text { \% do } \text { Trabalho } \\
\text { do Motor }\end{array}$ & $\begin{array}{l}\text { Trabalho } \\
\text { frenagem }(\text { MJ })\end{array}$ & $\begin{array}{l}\text { \% do Trabalho } \\
\text { do Freio }\end{array}$ \\
\hline Compressor A/C & $-3,12$ & 33,0 & 1,20 & 47,2 \\
Alternador & $-0,96$ & 10,1 & 0,37 & 14,6 \\
Bomba de óleo & $-0,44$ & 4,6 & 0,27 & 10,6 \\
Bomba d'água & $-0,17$ & 1,8 & 0,10 & 3,9 \\
Total Auxiliares & $-4,69$ & 49,5 & 1,94 & 76,3 \\
Propulsão & 9,46 & 100 & & 100 \\
Frenagem & & & & \\
\hline
\end{tabular}

Tabela 3. Trabalhos no ciclo FTP

O ciclo NEDC, composto de $66 \%$ urbano e $34 \%$ estrada, apresenta valores expressivos de energia gerada para propulsão sendo consumida nos auxiliares $(41,3 \%)$. Por outro lado, nos momentos onde há corte de combustível, os auxiliares contribuem na frenagem com 36,2\% do trabalho total requerido nesse ciclo. Em ambos os casos o compressor apresenta o maior trabalho.

Já no ciclo FTP, que é apenas urbano, mas em velocidades maiores que o ciclo NEDC, os valores de trabalho necessário para movimentar os auxiliares aumenta para 4,69MJ $(49,5 \%$ da energia do motor). No entanto a energia de frenagem realizada pelos auxiliares tem um aumento bem mais substancial, chegando a 76,3\% da energia total de frenagem requerida. Este aumento é devido, principalmente, às velocidades mais elevadas. Isto mantém o motor em situação de corte de combustível por mais tempo, possibilitando que os auxiliares contribuam mais na frenagem.

\section{CONCLUSÃO}

A análise dos resultados nos permite concluir que os auxiliares consumem uma grande parte da energia total produzida pelo motor a combustão, podendo chegar a 49,5\% no ciclo de consumo urbano FTP. 
Portanto é necessário que maior foco seja dado na otimização desses sistemas, seja pela movimentação por motores elétricos com melhor controle de carga, ou pelo estudo e otimização dos sistemas existentes. Em especial pode-se ressaltar o compressor de ar condicionado, sistema responsável por consumir até 33\% da energia produzida pelo motor, que hoje é controlado, em cargas parciais, principalmente pelo uso de embreagens, método altamente ineficiente.

Finalmente, apesar do grande auxilio que esses sistemas podem oferecer na economia dos freios, o uso de módulos especializados para nessa função, como retardadores ou sistemas de recuperação de energia cinética, deve apresentar resultados melhores e menos dependentes do ciclo aplicado.

\section{REFERÊNCIAS}

[1] ACEA, E. A. Car, Trucks and the Environment. Disponível em http://www.acea.be/ news/news_detail/cars_trucks_and the environment/. Acesso em: 20/05/2013

[2] KIM, K., HWANG, K., LEE, K., \& LEE, K. Investigation of coolant flow distribution and the effects of cavitation on water pump performance in an automotive cooling system.

International Journal of Energy Research. DOI: 10.1002/er. 1462. 16/09/2008.

[3] INAGUMA, Y. Friction torque characteristics of an internal gear pump. Journal of Mechanical Engineering Science. DOI: 10.1177/0954406211399659. 09/04/2011.

[4] NORM SAE J1343. Information Relating to Duty Cycles and Average Power

Requirements of Truck and Bus Engine Accessories. SAE. 2000

[5] BOSCH. Automotive Handbook (8 ${ }^{\text {a }}$ ed.). SAE International. 2011

[6] FRANKLIN, G., POWEL, J., \& EMAMI-NAEINI, A. Feedback Control of Dynamic

Systems (5a ed.). Prentice Hall. 2005

[7] GILLESPIE, T. D. Fundamentals of Vehicle Dynamics. SAE. 1992

[8] KLUGER, M., \& HARRIS, J. Fuel Economy Benefits of Electric and Hydraulic Off

Engine Accessories. SAE Technical Papers. Nro: 2007-01-0268. 2007

[9] ROMA, W. N. Introdução às Máquinas Hidráulicas. EESC - USP. 2006

\begin{tabular}{ll} 
ANEXO \\
Valores utilizados no simulador do veículo. \\
\hline Área Frontal & $2,552 \mathrm{~m}$ \\
Eficiência na Transmissão & 0,99 \\
Raio da roda & $0,3048 \mathrm{~m}$ \\
Ganho Dianteiro do Freio & $1,469 \mathrm{~N} \cdot \mathrm{m} / \mathrm{psi}$ \\
Ganho Traseiro do Freio & $1,017 \mathrm{~N} \cdot \mathrm{m} / \mathrm{psi}$ \\
Coeficiente de arrasto & 0,358 \\
Massa & $1200 \mathrm{~kg}$ \\
Eficiência da Correia & 0,98 \\
\hline
\end{tabular}

